which so often mark the beginning of active trouble raise first the blood sugar and subsequently the C.S.F. sugar level, ${ }^{1}$ and should the latter alone be estimated an apparently normal reading may be obtained. But this correlated with a blood-sugar reading taken at the same time will give a ratio below the lower limits of normality should tuberculous meningitis be present.

The level of C.S.F. chlorides is dependent on that of blood chlorides and is not, to my mind, of much diagnostic significance. If vomiting is a marked symptom, then they will both be lowered in the early stages, but I had several cases in which they approximated to normal even in the terminal stages of the disease. My results were published in detail in $1939 .^{2}$

In view of the number of letters which appear in these columns drawing the attention of more recent workers to already published results which they have apparently overlooked, might I put in a plea that more use should be made of the Quarterly Cumulative Index Medicus?-I am, etc.,

Kempston, Bedford. Esther H. WELbourN.

1 McLean, M. B., Arch. Dis. Childh., 1936, 11, 247.

2 Herdry, E., ibid., 1939, 14, 307.

\section{Tuberculosis in the Family}

SIR,-It may be interesting to recall some figures of my own ${ }^{1}$ which confirm the statement of Dr. C. O. Stallybrass in his excellent article "Tuberculosis at the Crossroads" (Feb. 5, p. 207). He says that "family contacts of known cases form at least one-third of the cases of tuberculosis.". Some years ago with the help of all the London tuberculosis officers I was able to collect information on 6,933 new cases of tuberculosis with regard to their previous association with other cases of the disease within the intimate family circle.

In 2,167 instances, or approximately $31 \%$ of all cases, there was a history of household contact of some sort thought worthy of note, and in 350 of these there was more than one such contact. Investigation, however, concentrated on "important" contact-i.e., where a previously affected member of the immediate family was alive and suffering from tuberculosis, or where death had occurred from pulmonary tuberculosis in the immediate family within the preceding five years. A detailed analysis showed that 3,021 T.B.-plus male and 2,158 T.B.-plus female patients coming for residential treatment for the first time had been investigated and that the frequency with which contact with a previous case was noted was seen to diminish with increasing age. For instance, while $15 \%$ of all males with positive sputum showed previously important contact with the disease in the intimate family circle, the percentages ranged from 21 and 23 in the 16-20- and 21-25-year groups respectively, down to 10 in those over 40 years of age. As age advances a similar diminution in the importance of contact with a previous case was also seen in females.

Females throughout, however, showed a larger incidence of contact with a previously known case. Thus at all ages $22 \%$ had been in contact with a previous case in the intimate family circle, whilst the percentages ranged from 31 in the $0-15$-year group down to 17 in those over 40 years of age. This greater incidence of contact as a factor in the causation of the disease in females as compared with males was thought to be due to the wider opportunities of exposure to infection in the family by reason of domestic and nursing duties. Kissing also might be a factor.

As regards the relationship of what might be called the "infecting" case, it was noted that the original cases were in parents in $20 \%$ in males compared with $27 \%$ in females. A tuberculous parent seemed to be a greater danger to a daughter than to a son. Here again the reason was possibly the special position of women in the household in regard to nursing and domestic duties and the like. Approximately three-quarters of all "infecting" cases were either living cases of pulmonary tuberculosis with positive sputum or cases which had succumbed to pulmonary tuberculosis within the immediately preceding five years.

I emphasized as a result of this work that contact with a previously diagnosed case of tuberculosis in the family was of sufficiently common occurrence in the history of new patients to stimulate examination of contacts in the attempt to find early cases, and I would agree now with Dr. Stallybrass that data of this description should also stimulate us to press on with trials of vaccination by means of B.C.G. in these and other vulnerable classes of the community.-I am, etc., Brentwood, Essex.

F. J. Bentley.

1 Annual Report of the L.C.C., 1937, 3 (Part I), 45

\section{Tuberculosis at the Crossroads}

SIR,--In his interesting study of "Tuberculosis at the Crossroads" Dr. C. O. Stallybrass (Feb. 5, p. 207) throws some incidental light on a possible signpost which may be of value. Those of us who for long have been gravely suspicious that among nurses there was a relatively higher incidence of tuberculosis will have noted his words that, while the mortality rate in this group was not higher than among other young women of similar age, there "would seem to be a higher rate of morbidity." The distinction is significant and understandable, as nurses should be favourably placed as to early discovery and treatment, though at a higher exposure risk.

Surely, however, "higher morbidity," if recognized, should hasten the day for B.C.G. protection, in which this country has lagged so far behind Scandinavia. While statistics are lacking, there is little indication that our beds, closed for lack of staff, are being filled. Parents hesitate about health hazards for their daughters, and our profession is uneasy. If we recognize a signpost at the crossroads perhaps we may the sooner reach Norway's happy position of having "waiting beds" instead of the "waiting lists" of which Dr. Stallybrass speaks.-I am, Northwood, Mddx.

Esther Carling.

\section{Whither Tuberculosis ?}

SiR,-Now that Drs. G. Lissant Cox (Dec. 25, 1948, p. 1118) and A. S. Hall (Jan. 8, p. 70) have had their say and the British Medical Journal has made a pronouncement (Feb. 5, p. 226) on the above subject, may the voice of one who has worked in the tuberculosis service as long as the gentlemen mentioned, but who does not see eye to eye with them in this matter, be heard ? Or are we to be told that B.M.J. locutus est, causa
finita est?

To put the matter in its proper perspective a little personal history is necessary. I was appointed district tuberculosis officer by the Derbyshire County Council in December, 1918, on a salary of $£ 500$, plus the right to private consulting practice in tuberculosis and diseases of the chest. As I had come into the tuberculosis service from the Indian Medical Service the system of a fixed salary for public work combined with consulting fees for private work was no novelty to me. I soon found that in my district a chest disease of great clinical interest had long been known among the gritstone masons, ganister miners, and cutlery grinders, and naturally this condition and its supposed relation to pulmonary tuberculosis attracted my attention. When in' due coure the first silicosis compensation scheme was put into operation, the work of examining the employees in the scheduled industries devolved upon me. For this work I was, of course, independently paid.

Near Buxton is situated the research station of the Safety in Mines Research Board, and there I made the acquaintance of
Professor J. S. Haldane and many other scientists interested in questions regarding the production of dusts in industry and their effects on health. I began to see in front of me possibilities of an interesting career and life study in diseases of the chest, and I built myself a house in Buxton with a consulting-room and a waiting-room
for my private patients.

Alas, "the best-laid schemes . .." The Home Office decided to "keep its ain fish guts for its ain fish maws," and appointed special district boards under its medical department for the routine examination of the workmen in the scheduled industries. Officially silicosis was taken out of my hands, but unofficially I continued to see suspected and established cases of silicosis and to make my investigations. Now, after thirty years, I can claim to have made some contribution to knowledge regarding that and kindred diseases.

In the nineteen twenties certain Divisions of the B.M.A. began to object to private consulting practice being undertaken by salaried clinical officers. The question became acute about 1924. Our division of the B.M.A. held a meeting in Derby and decided to support the right of clinical officers to private consulting practice. A was elected as divisional representative and directed to move the resolution at the Representative Meeting at Bath. There, alas, I made the greatest mistake of my life, a mistake which ever since I have bitterly regretted and of which I am thoroughly ashamed. The 